\title{
dspace.vutbr.cz
}

\section{Investigation and comparison of spray characteristics of pressure-swirl atomizers for a small-sized aircraft turbine engine}

ĎURDINA, L.; JEDELSKÝ, J.; JÍCHA, M.

International journal of heat and mass transfer

2014, vol. 78, November 2014, pp. 892-900

ISSN: 0017-9310

DOI: https://doi.org/10.1016/.i.ijheatmasstransfer.2014.07.066

Accepted manuscript

(C) 2014. This manuscript version is made available under the CC-BY-NC-ND 4.0 license (http://creativecommons.org/licenses/by-nc-nd/4.0/), doi:

https://doi.org/10.1016/j.ijheatmasstransfer.2014.07.066

Final version available from https://www.sciencedirect.com/science/article/pii/s0017931014006553 


\title{
Investigation and Comparison of Spray Characteristics of Pressure-Swirl Atomizers for a Small-Sized Aircraft Turbine Engine
}

\author{
Lukas Durdina*, Jan Jedelsky**1 and Miroslav Jicha** \\ * Laboratory for Analytical Chemistry, Empa, Überlandstrasse 129, 8600 Dübendorf, Switzerland \\ **Faculty of Mechanical Engineering, Brno University of Technology, Technicka 2896/2, 61669 \\ Brno, Czech Republic \\ lukas.durdina@empa.ch, jedelsky@fme.vutbr.cz and jicha@fme.vutbr.cz
}

\begin{abstract}
The quality of liquid fuel atomization highly affects the formation of gaseous pollutants and particulate matter emissions from combustion processes. Spray characteristics of two geometrically different pressure-swirl atomizers for a turbojet engine in light aircraft were measured on a cold test bench. A spill-return atomizer and its intended replacement simplex atomizer were investigated using Particle Image Velocimetry (PIV) and PhaseDoppler Anemometry (PDA). Single-camera and stereoscopic PIV measurements yielded velocity distributions in the axial cross-section of the spray cone. PDA measurements provided drop-size distribution and axial velocity data. Acquired results reveal significant differences in spray characteristics of the nozzles investigated at the same fuel injection pressures. The simplex nozzle produced spray with Sauter mean diameters lower by 5-20 $\mu \mathrm{m}$ depending on the regime, its spray was more stable but its shape greatly varied with fuel injection pressure. These differences are discussed in detail, their analysis indicate a potential for spray improvement provided by the novel atomizer design and elucidates the possible impact of the nozzle replacement on the combustion process.
\end{abstract}

Keywords

spray characteristics; pressure-swirl atomizer; particle image velocimetry; phase-Doppler anemometry; spillreturn; droplet size

\section{Introduction}

European aviation has pledged to reduce $\mathrm{NO}_{\mathrm{x}}$ emissions by $80 \%$ by 2020 via improvements of the combustor technology [15]. Characteristics of fuel nozzles, such as the spray dispersion angle, drop-size and velocity distribution and evaporation have a significant influence on the combustor performance. Spray quality affects stability limits, combustion efficiency and pollutant emission levels. Good atomization quality promotes the fuel evaporation and decreases the demand of ignition energy [8].

Pressure-swirl atomizers convert the liquid pressure into kinetic energy by creating a condition of high velocity between the liquid discharged from the nozzle and the surrounding gas. Inside the nozzle, liquid is fed through tangential ports into a swirl chamber mounted upstream of the discharge orifice. The swirling liquid flow under the action of the centrifugal force creates an air-cored vortex in the swirl chamber. The liquid flows through the discharge orifice and spreads in the form of a conical liquid film. This thin layer withstands the spread of instabilities inside the liquid as well as on its surface, which result from the high slip velocity between the liquid sheet and the surrounding air. The instabilities cause the breakup of the liquid sheet into ligaments and then into drops in the form of a hollow-cone spray. Droplet-droplet collisions and the aerodynamic forces further disintegrate the drops into smaller droplets further downstream of the nozzle orifice [9].

A drawback of the simplex nozzles is the poor atomization quality at low inlet pressures. This disadvantage has been overcome in the spill-return nozzles which basically are simplex nozzles with a passage in the rear wall of the swirl chamber (Figure 2). This passage is connected via a spill line with the fuel tank. When the spill is closed, the atomizer operates as a standard simplex nozzle. Spill-return atomizers have better atomization quality than simplex nozzles for low discharge flow rates when the major fraction of the inlet flow rate is diverted to the spill return. Usually a high liquid flow rate is maintained in the feed line and the amount of the discharged liquid is governed by the spill flow rate. The liquid sheet thickness and the size of droplets that emerge after its breakup decrease with increasing inlet flow rate and do not depend on the flow rate of the discharged liquid [8]. However, the spray cone angle varies with the changes in the spill return flow rate which has a negative influence on combustion efficiency. Another drawback is the complicated flow metering. For these reasons, interest in this atomizer type for aircraft engine combustors has declined [8].

Spray characteristics and performance of simplex nozzles have been investigated widely over the last decades. Pioneering studies of the liquid film instabilities and breakup of liquid sheets generated by swirl atomizers

\footnotetext{
${ }^{1}$ Corresponding author. Tel.: +420 541143266
} 
were performed by Taylor [22] and Squire [21]. Rizk and Lefebvre [16, 17] studied internal flow and spray characteristics of pressure-swirl atomizers. Wang and Lefebvre [23, 24] further studied mean drop sizes and influence of ambient air pressure on pressure-swirl atomization. More recent experimental studies have focused on the improvement of spray characteristics using advanced laser diagnostic techniques, such as Phase-Doppler Anemometry (PDA) [2, 4, 13], laser diffraction/scattering [26] and Laser Induced Fluorescence (LIF) [7, 10], and high-speed camera measurements [28].

Spill-return nozzles have been investigated in a smaller scale than simplex nozzles. An early implementation of a fuel system for a jet engine with spill control was described by Carey [3]. Rizk and Lefebvre [18, 19] investigated spray characteristics and drop-size distribution of spill-return nozzles with kerosene as the test fluid. Most recently, Nasr et al. [14] have developed a new spill-return atomizer which can produce a fine spray for very low flow rates.

We used laser diagnostic techniques Particle Image Velocimetry (PIV) and PDA to investigate spray characteristics of two miniature pressure-swirl atomizers for the combustor of an aircraft turbojet engine, designed for experimental aircrafts and gliders. The original fuel atomizer (Nozzle 1) is a spill-return type which had been used for several decades. This nozzle was intended to be replaced by a newly developed simplex nozzle (Nozzle 2). Analysis of the differences between these two nozzles indicate the potential for spray improvement provided by the novel atomizer design and elucidates the possible impact of the nozzle replacement on the combustion process. This study is aimed to improve the understanding of processes during the pressure-swirl atomization with emphasis to combustion application.

\section{Experimental Methods}

The nozzles were tested on a cold test bench at room temperature and fuel pressure varying in the range corresponding to engine operation from idle to take-off setting. The inlet and spill line gauge pressures are summarized in Table 1. Aviation kerosene Jet A-1 was delivered by a gear pump from a 20-liter tank through Siemens Mass 2100 Coriolis mass flow meter and was injected vertically into a collecting vessel with mist extraction. As can be seen in Figure 1, the nozzle holder was equipped with a shut-off valve for the spill line. Flow rate and gauge pressure in the spill line were controlled with a rotameter equipped with a fine metering valve. Collected fuel was pumped by a solid state pump back into the tank.

The outer dimensions of the two nozzles were identical and differed only in the internal geometry. The internal geometry and dimensions of Nozzle 1 are presented in Figure 2 and listed in Table 2, respectively. In the both nozzles, fuel was fed into the spherical swirl chamber through two tangential ports with square crosssection. Nozzle 2 was designed to produce a finer spray. Its orifice diameter was $0.2 \mathrm{~mm}$, other internal dimensions of this nozzle were not available.

Table 1 Operating regimes of the tested nozzles.

\begin{tabular}{cccc}
\hline $\begin{array}{c}\text { Regime } \\
\text { no. }\end{array}$ & Inlet pressure [kPa] & Nozzle 1 & Nozzle 2 \\
\hline 1 & 200 & 50 & 200 \\
2 & 340 & 0 & 340 \\
3 & 690 & 0 & 690 \\
4 & 1000 & 0 & 1000 \\
5 & 1000 & 400 & - \\
\hline
\end{tabular}

Drop size and velocity were measured using a Dantec PDA system. This 1-component system was equipped with the Ion Laser Technology 5500A-00 Ar-Ion+ laser (max. power output $300 \mathrm{~mW}$ ). The spectral line 514.5 $\mathrm{nm}$ of the CW-laser beam with power up to $40 \mathrm{~mW}$ and horizontal polarization was split using the $58 \mathrm{~N} 10$ transmitting optics into two parallel beams $60 \mathrm{~mm}$ distant. The focal length of the transmitting was $500 \mathrm{~mm}$, which results in a half-intersection angle between the beams of $3.43^{\circ}$. The frequency of one of the beams was shifted by $40 \mathrm{MHz}$. This configuration leads to a fringe separation of $4.3 \mu \mathrm{m}$. First-order refracted light was collected using Dantec 57X10 receiving optics equipped with three photo-detectors. The focal length of the receiving lens was $500 \mathrm{~mm}$ and the scattering angle $\varphi$ was set to $69^{\circ}$. The setup enables us to measure the drop size up to $220 \mu \mathrm{m}$. 


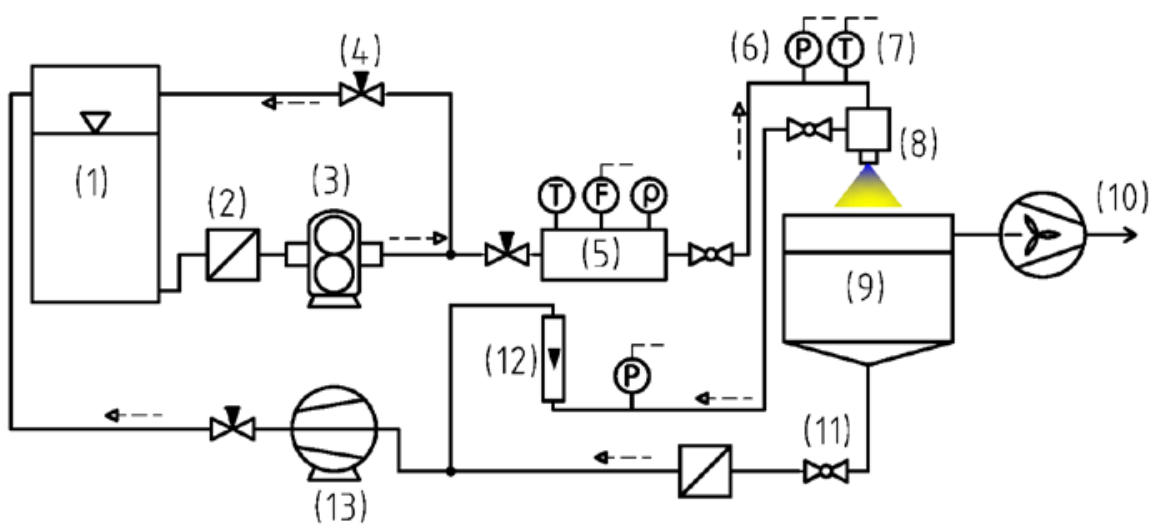

Figure 1 Test rig: (1) fuel tank, (2) filter, (3) gear pump, (4) needle valve, (5) mass flow meter, (6) pressure sensor, (7) temperature sensor, (8) atomizer in a holder, (9) collecting vessel, (10) axial fan and mist extraction, (11) ball valve, (12) rotameter, (13) fuel pump. Dashed lines leading from the instruments represent signal outputs for the data logging system.
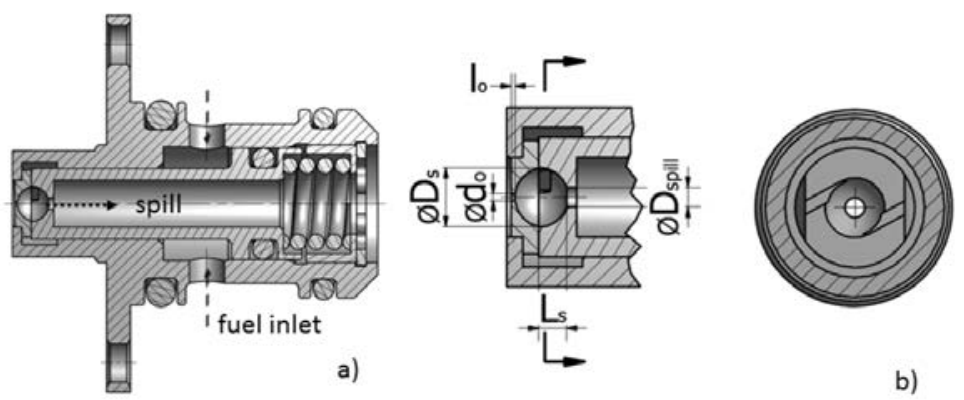

b)

Figure 2 a) section view of Nozzle 1 with dimensions given in Table 2; b) detail view on the swirl chamber.

Table 2 Internal geometric dimensions of the Nozzle 1.

\begin{tabular}{ccc}
\hline $\begin{array}{c}\text { Geometric } \\
\text { dimensions }\end{array}$ & Value & unit \\
\hline$d_{o}$ & 0.36 & $\mathrm{~mm}$ \\
$l_{o}$ & 0.2 & $\mathrm{~mm}$ \\
$A_{o}$ & 0.10178 & $\mathrm{~mm}^{2}$ \\
$D_{s}$ & 3.0 & $\mathrm{~mm}^{2}$ \\
$A_{p}$ & 0.72 & $\mathrm{~mm}^{2}$ \\
$L_{s}$ & 1.41 & $\mathrm{~mm}$ \\
$D_{\text {spill }}$ & 1 & $\mathrm{~mm}$ \\
\hline
\end{tabular}

A Dantec 58N50 signal processor was set to measure velocity within the range of -26 to $26 \mathrm{~m} / \mathrm{s}$ at $12 \mathrm{MHz}$ bandwidth. The obtained data were evaluated using BSA Flow Software v2.1. Experimental setup for the PDA measurements is shown in Figure 3. Radial scans of the spray profiles were carried out in two planes -25 and $50 \mathrm{~mm}$ downstream of the discharge orifice with $10 \mathrm{~mm}$ distance between the measurement points. Only results in the $50 \mathrm{~mm}$ distance are shown here for brevity (Figures 9-12).

Both planar single-camera and stereoscopic PIV systems from TSI Inc. (Figure 4) were used for measurements of the velocity distribution. A vertical laser light sheet of approximately $1 \mathrm{~mm}$ thickness was produced by a double-pulse Nd:YAG laser (NewWave Research Gemini, $50 \mathrm{~mJ}$ per pulse, max. repetition rate $15 \mathrm{~Hz}$ ) conditioned through a cylindrical lens. The light sheet illuminated an axial cross-section of the spray. In the case of the single-camera system, a CCD camera was oriented perpendicular to the light sheet and the processed data yield two-component velocity field. In the stereoscopic configuration, cameras were placed on the same side of the light sheet (back- and forward light scatter) with the full stereoscopic viewing angle $2 \theta=80^{\circ}$. This angle pro- 
vides sufficient accuracy for the estimation of the out-of-plane velocity component [1]. Data processing of the stereoscopic measurements yields three-component velocity vector field. Timing of the PIV system was controlled by a TSI LaserPulse synchronizer in concert with an acquisition computer. The PIV images were acquired and processed by TSI Insight 3G 10.0 software package. For each experimental run, 1000 paired images were captured and subsequently interrogated using a recursive cross-correlation algorithm. The first pass and second pass spot sizes were $64 \times 64 \mathrm{px}$ and $32 \times 32 \mathrm{px}$, respectively. Each of the experimental runs, differing in the inlet pressure, required different time delay between laser pulses (from 20 to $50 \mu \mathrm{s}$ ) in order to minimize the out-ofplane motion of particle images between the paired captures, as well as the in-plane loss of correlation due to large particle displacement at higher velocities.

Spray droplets were used as the tracer (seeding) particles for calculation of the velocity vectors. PIV is not able to correctly trace the velocity in areas with insufficient particle number such as the near-nozzle region where liquid sheet occurs only. Therefore, velocity field in the near-nozzle area is not displayed in Figures 7 and 8.

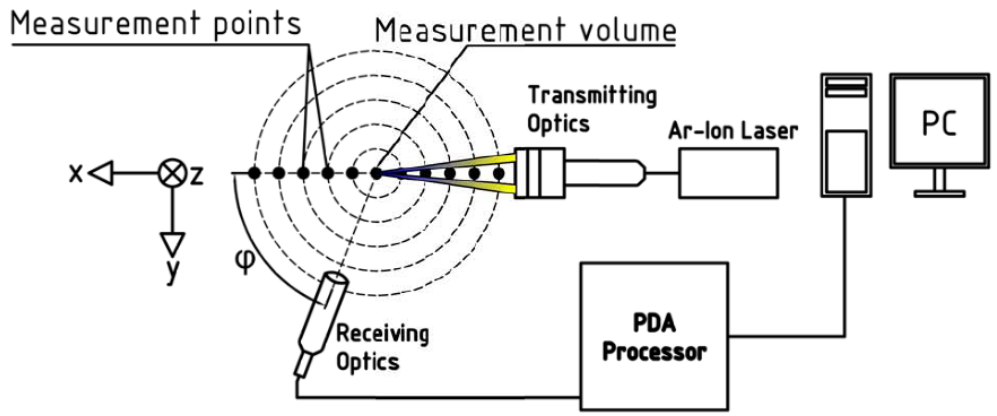

Figure 3 Experimental setup for the PDA measurements.

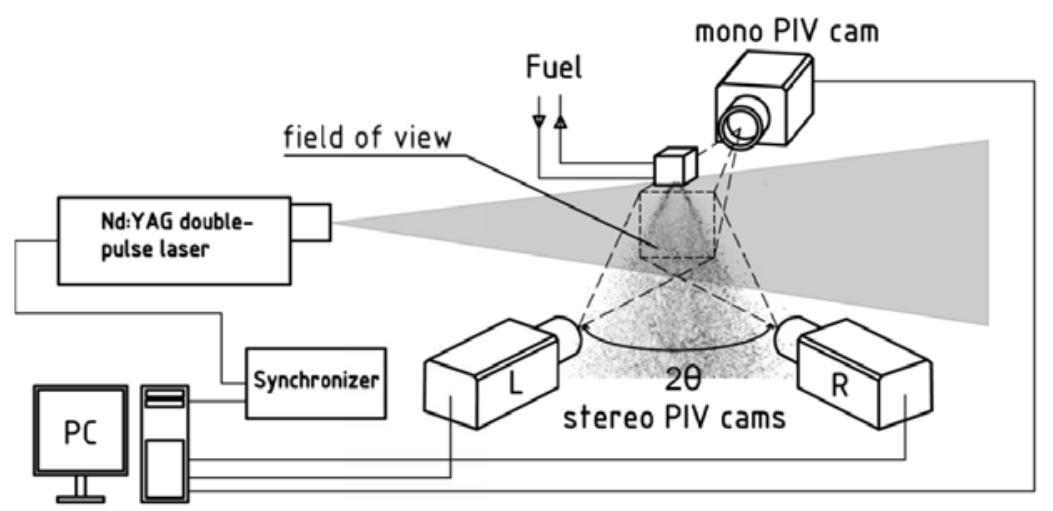

Figure 4 Experimental setup for the PIV measurements.

\section{Results and Discussion}

Differences in the spray characteristics of the two nozzles were investigated both qualitatively in terms of spray morphology from the PIV photographs and quantitatively by the droplet velocity and size spectra retrieved from the laser diagnostics.

\subsection{Spray Morphology}

Single-pulse spray images obtained from the single-camera PIV measurements were used for qualitative description of the spray morphology. Figure 5 shows axial sections of the sprays, as illuminated using the PIV laser sheet, generated by the two nozzles for the each studied operating regime. Figures $5 a-5 e$ concern spill-return Nozzle 1, whereby Figures 5a and 5e show the regimes with the spill line open. Figures 5f-5i deal with the simplex Nozzle 2.

Nozzle 1 produced a noticeable fraction of large drops dispersed in the whole spray cone at lower inlet pressures (Figures 5a-5c). Figure 5a shows the conical liquid film emerging from the exit orifice. Its tulip shape terminates in a tattered edge where the liquid disintegrates into ligaments and consequently into droplets. With increasing pressure differentials the spray core is formed by smaller droplets due to the drag force caused by gas entrainment towards the spray core and larger droplets can be observed at the spray periphery (Figures 5c, 5d). Comparing Figures 5d and 5e, we can see that the increase in spill flow decreased the droplet size in the spray core. It is due to the decreasing thickness of the liquid sheet. Flow rate regulation via the spill-return valve also changed the spray cone angle. The cone angles $2 \alpha$ (Figure 6) described here, were measured as the maximum 
angle between the slopes of the liquid sheet near the exit orifice [9]. These cone angles were estimated from averaged PIV captures shown in Figure 6 and are summarized in Table 3. Increase in spray cone angle is found at both tested regimes with active spill regulation against the regimes with the closed spill line (Figures 5a, 5e). Nozzle 1 exhibited a moderate widening of the spray cone with increasing inlet pressure until the pressure reached approximately $600 \mathrm{kPa}$. Consecutive inlet pressure increase did not cause any further increase of the cone angle; so the cone angle is defined by the internal geometry of the atomizer.
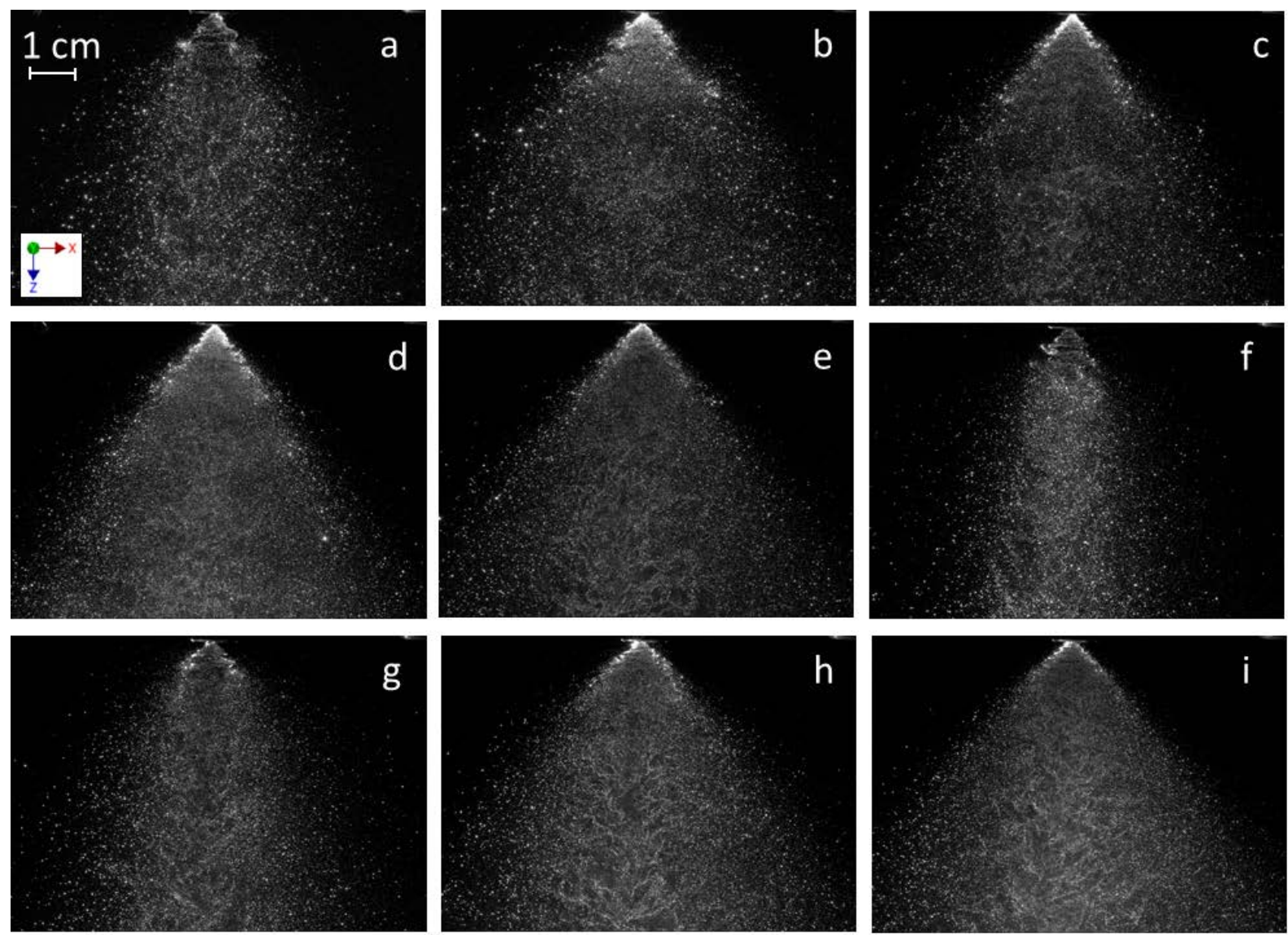

Figure 5 Spray visualizations: a) N1 200/50 kPa; b) N1 340 kPa; c) N1 690 kPa; d) N1 1000 kPa; e) N1 1000/400 kPa; f) N2 200 kPa; g) N2 340 kPa; h) N2 690 kPa; i) N2 1000 kPa.

The spray generated by Nozzle 2 strongly depended on the governing pressure drop. At the lowest used gauge pressure, the fuel film is constricted by the surface tension force and formed an onion-shaped bubble which collapsed near the spray axis (Figure 5f). Therefore, resulting drops are concentrated around the spray axis as well, creating a full-cone spray. As the inlet pressure increases, and so does the kinetic energy of the atomized liquid, the liquid film straightens and its thickness attenuates. The film breaks up due to internal instabilities, promoted with the drag force, into filaments and drops in a short distance from the exit orifice into a hollowcone spray with well-defined shape (Figures $5 \mathrm{~h}, 5 \mathrm{i}$ ). This process is consistent with other published descriptions of the simplex nozzle behaviour [9, 16, 17, 23, 24]. Figures 5g-5i suggest the spray core consisted of a number of smaller droplets, and the droplet size increased with radial distance. Droplet clusters can be seen in the spray core as the result of the interaction of small droplets with the ambient air.

Comparing the spray structure of the two nozzles, spray core of Nozzle 1 consisted of larger droplets that are more prone to be trapped by the air. The effect of droplet clustering on the combustion will probably not be significant as the core consists of low fraction of the total fuel mass, however reactive testing is necessary to confirm this hypothesis. The spray generated by Nozzle 2 widened at first rapidly with increasing inlet pressure. At inlet pressure values above $600 \mathrm{kPa}$, cone angle approached slowly its final value defined by the internal geometry and was reached at about $1 \mathrm{MPa}$, as summarized in Table 3. A visual observation of the both sprays showed that Nozzle 2 produced more stable and steady spray. 
Table 3 Spray cone angle $2 \alpha$ for different operating regimes with indication of the corresponding image in Figures 5-7.

\begin{tabular}{ccc}
\hline $\begin{array}{c}\text { Operating } \\
\text { regime }\end{array}$ & $\begin{array}{c}\text { Nozzle } 1 \\
2 \alpha[\mathrm{deg}]\end{array}$ & $\begin{array}{c}\text { Nozzle } 2 \\
2 \alpha[\mathrm{deg}]\end{array}$ \\
\hline 1 & $80(\mathrm{a})$ & $60(\mathrm{f})$ \\
2 & $74(\mathrm{~b})$ & $78(\mathrm{~g})$ \\
3 & $76(\mathrm{c})$ & $86(\mathrm{~h})$ \\
4 & $76(\mathrm{~d})$ & $88(\mathrm{i})$ \\
5 & $86(\mathrm{e})$ & - \\
\hline
\end{tabular}
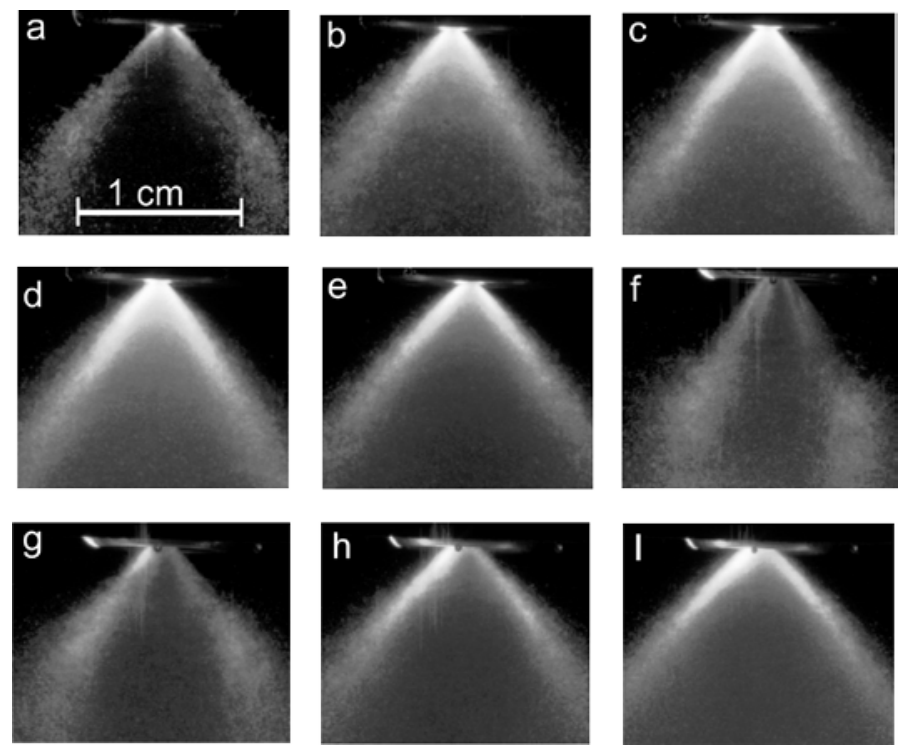

Figure 6 Averaged PIV captures for spray cone angle measurement, labelling of the regimes is the same as in Figure 5.

\subsection{PIV droplet velocity analysis}

Processed PIV captures provide visualization of the droplet velocity magnitude in the axial cross-section of the spray from approximately $10 \mathrm{~mm}$ below the nozzle orifice. The results shown in Figure 7 have the same labelling of the regimes as in the Figures 5 and 6 above. All the flow fields in Figure 7 show that the velocity is highly spatially variable with its maximum near the exit orifice.

Velocity distribution in the spray generated by Nozzle 1 indicates a hollow-cone formation from regime 2 (340 kPa inlet pressure) up to the maximum pressure setting. The main-stream jet (droplets following the original liquid sheet direction) propagated with a roughly parabolic velocity profile and decelerated from both edges by the surrounding still air. The original liquid momentum was well conserved up to the distance of $\sim 15 \mathrm{~mm}$. Decreasing droplet size during the breakup process and increasing interfacial area (widening spray cone) rapidly intensify the droplet interaction with air with downstream distance and the droplet momentum quickly decreases. So the velocity decay along distance from the nozzle is very intense at the high pressure and namely at opened spill line regimes. The main stream droplets decelerated roughly to one half of their original velocity when moving from $z=15$ to $30 \mathrm{~mm}$ and again so from 30 to $45 \mathrm{~mm}$ for regime 5 while at regime 2, with larger droplets and narrower spray cone, the deceleration to one half of the original velocity required droplet travel from $z=15$ to $45 \mathrm{~mm}$. The droplet velocity at axial distances larger than about $40 \mathrm{~mm}$ was always only a small fraction of the exit velocity.

In the spill-controlled regime, Nozzle 1 generated finer droplets which, due to their lower kinetic energy, decelerate in a short distance downstream from the discharge orifice (Figure 7a). Spray generated in the regimes 24 had similar spatial velocity distribution, differing in the velocity magnitude in the proximity of the nozzle orifice (Figures 7b-7d). As we can see in Figure 7e, spray generated in the spill-controlled regime at $1000 \mathrm{kPa}$ inlet 
pressure exhibits lower velocity magnitude of droplets than the regime without spill return at the same inlet pressure, what is related to the thinner liquid sheet and thus the smaller droplets.

Velocity magnitude distribution in the spray generated by Nozzle 2 shows a significant dependence on the inlet pressure for regimes 1 and 2 (Figures 7f, 7g). For the lowest pressure, fluid mass was concentrated around the spray axis; high velocity region is located under the break-up spot of the liquid sheet bubble. With increasing gauge pressure, spray mass shifted towards the spray periphery. Droplet dynamics leads to deformation of the velocity profile with increasing axial distance. Ambient air significantly decelerates drops with increasing distance from the nozzle orifice; the droplet momentum decay rate was higher than in the case of Nozzle 1 (well seen if one compares corresponding images in Figure 7: b with g, c with h, and d with i) due to smaller droplets and wider cone angles. For inlet pressures above $340 \mathrm{kPa}$, Nozzle 2 generated a hollow-cone spray. Although the spray core was formed by a large number of small drops, the mass flux in the central area represents only a fraction of the total mass flux in the axial direction due to small volume of these drops. With increasing gauge pressure, the cone angle increased first significantly (Figures 7f, 7g) and then only moderately (Figures 7h, 7i), what is also evident from the spray photographs in Figure 5.

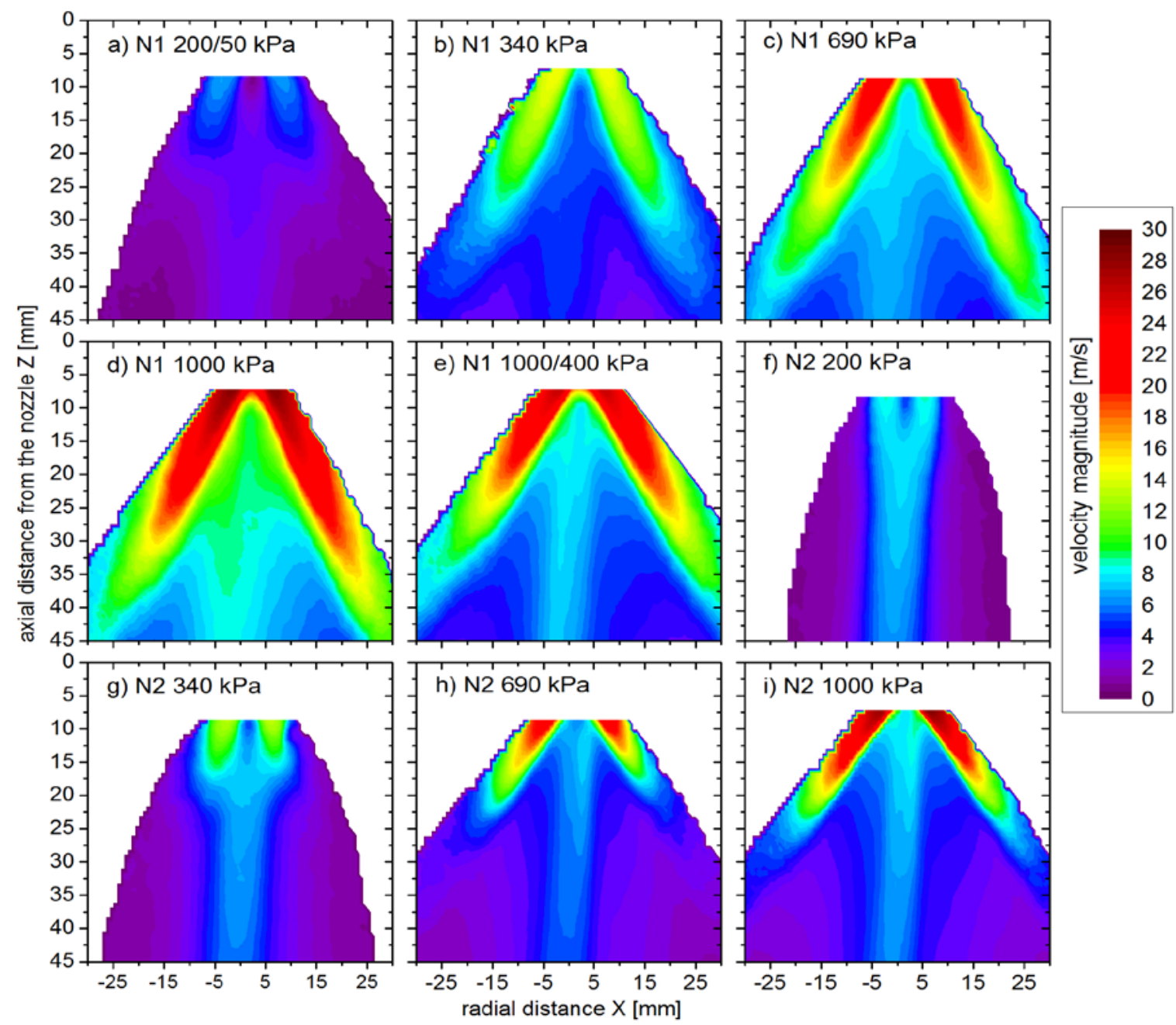

Figure 7 Velocity magnitudes from single-camera PIV measurement for the both nozzles.

Single-camera PIV is unable to resolve the out-of-plane velocity component (i.e. tangential velocity component for our experimental setup with the axially positioned laser sheet) and the effect of this component on the velocity field is lost. Stereoscopic PIV measurements were done in order to disclose the extent to which the outof-plane component of particle velocity affects the velocity magnitude when compared to the results obtained with single-camera arrangement. Comparison of the velocity magnitudes and estimates of the tangential velocity components obtained from the stereoscopic PIV for Nozzle 1 in operating regime 5 and Nozzle 2 in operating regime 4 is shown in Figure 8. It is obvious that the velocity distributions in Figures 8a and 8c correspond to the 
single-camera results given in Figure 7. Tangential component of the droplet velocity is expected to attain the highest values downstream after the break-up of the liquid sheet when the droplets are still driven by the angular momentum of the swirled liquid. This behaviour was confirmed by our measurements (Figures 8b, 8d).

Tangential particle motion with similar velocity profiles was detected in the both cases. Spray droplets at the spray periphery in a short distance from the discharge orifice exhibit a tangential displacement in respect to the spray axis. The tangential velocity component was highly spatially variable and it reached up to $4 \mathrm{~m} / \mathrm{s}$ at the highest pressure setting. It decayed close to zero with increasing downstream distance. Influence of this velocity component on the velocity magnitude seems to be insignificant since the estimated tangential velocity was of one order of magnitude lower than the axial velocity component in the inspected region of the spray. Details on the tangential velocity component and different PIV configurations in the pressure-swirl spray can be found in [5].

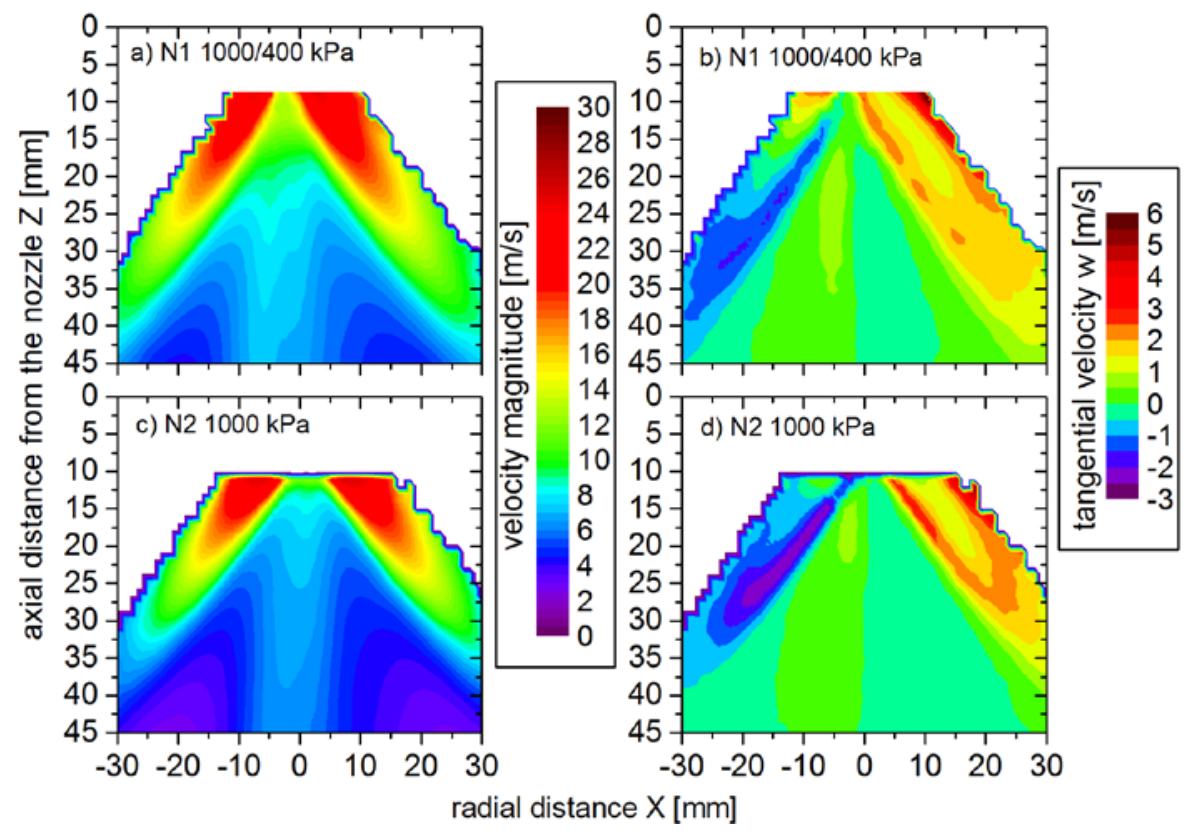

Figure 8 Velocity fields obtained from the stereoscopic PIV for the highest injection pressure regimes of the two nozzles: velocity magnitudes (left), out-of-plane velocity component (right).

\subsection{Spatial distribution of droplets}

A detailed inspection of the spray visualizations (Figure 5) and velocity fields (Figure 7) allows explaining the spatial distribution of the spray droplets. The droplet distribution follows primarily from geometry of the discharged liquid structures and their flow character; interaction of droplets with surrounding air and their dynamics secondarily affect the droplet fate. Liquid sheet, which collapses after discharge the lowest pressure, produces a full-cone spray with the both nozzles. Fully developed conical liquid sheet at sufficient inlet pressure (about $500 \mathrm{kPa}$ for the both nozzles) generates a hollow conical spray structure.

The spray core contains a number of droplets in the both modes, but their characteristics differ. Inside-cone droplets in the full-cone mode are as coarse as droplets in the rest of the spray and fast compared to the rest of the spray (e. g. Figure $5 \mathrm{f}$ and $7 \mathrm{f}$ ); they move due to inertia into the central zone after the bulk liquid breakup. The conical liquid film in the hollow-cone mode (e. g. Figure $5 \mathrm{i}$ and $7 \mathrm{i}$ ) breaks up into droplets with a wide size range. Large droplets keep their original trajectory while small droplets are forced to move into the spray centre due to the entrained air flow. These droplets feature air driven motion with a rather low axial velocity (except the near centreline area, as discussed below) and a clustering tendency (namely with Nozzle 2). They are abundant due to their long residence time and are thus well evidenced in PIV images (the number of droplets dispersed in the spray centreline produces a large amount of signals for PIV, the velocity calculation would not be actually possible without their sufficiently high concentration) but they contain very small fraction of the total liquid volume (depends on the third power of their diameters). Such high droplet number (or at least number sufficiently high for velocity or drop-size measurements) was documented by other investigations of hollow-cone sprays from pressure-swirl atomizers [2, 10-12, 20, 25, 26]. 


\subsection{PDA axial droplet velocity analysis}

A high local axial velocity was found near the spray centreline for the both atomizers at all operating regimes in the whole investigated range of axial distances from the orifice. This effect is clearly visible in the radial profiles of the axial velocity from PDA measurements (Figures 10 and 12) that are very similar to the PIV results at the maximum displayed axial distance of $45 \mathrm{~mm}$ in Figures 7 and 8 . The central velocity peaks were resolved in PDA profiles the same way as in the PIV images. The velocity of the central high-speed stream decreased slowly with distance. This deceleration is slower than droplet deceleration in the main-stream spray which is unexpected as central part of the spray contains smaller droplets than the main-stream spray; small droplets are supposed to be less affected by gravity and more tending to decelerate due to drag forces. We also did not find any flow structure in the PIV velocity data that could support this effect.

We hypothesise that the central droplets flow in a cloud formation which helps to keep their momentum while the main-stream droplet structure expand with downstream distance and its interaction with surrounding air increases. The flow field with high centreline velocity were found also by Madsen [11], Santolaya et al. [20] and Yang et al. [27] (all the works without any explanation for this effect) while other works [2, 6, 25] show local minima of axial velocity in the spray centreline. Full explanation of these differences in the centreline velocity behaviour would require further investigations but it is not significant as the effect of the centreline spray part on the combustion process is weak.

\subsection{PDA droplet size analysis}

The particle size spectra generated by the two nozzles changed differently with increasing inlet pressure. As shown in Figure 9, the Sauter mean diameter (SMD) of droplets in the spray of Nozzle 1 changed significantly with increasing gauge pressure and radial distance. Inversely bell-shaped radial profiles of SMD appear at all pressure regimes. The SMD span within radial profile increased from $63 \mu \mathrm{m}$ (from 59 to $122 \mu \mathrm{m}$ ) for regime 1 up to $89 \mu \mathrm{m}$ (from 17 to $106 \mu \mathrm{m}$ ) for regime 5 . This radial size variability results from the size-dependent interaction of droplets with the surrounding air: small droplets are trapped away from their original path and transported into the spray centre while larger droplets resist this effect.

In our particular interest were the results of the spill-controlled regimes of Nozzle 1 compared to the regimes without spill return. Comparing the axial droplet velocity at 200/50 kPa and $150 \mathrm{kPa}$, a slight decrease can be observed for the former regime. This is caused by the lower kinetic energy of droplets generated in this regime. With increasing inlet pressure up to $700 \mathrm{kPa}$, SMD values decreased significantly in the spray centre. Further pressure increase did not affect SMD significantly. However, in the spill-controlled regime 1000/400 kPa we can see that the SMD of droplets in the centre dropped below the SMD values at $1000 \mathrm{kPa}$. Droplet velocity at $1000 / 400 \mathrm{kPa}$ dropped markedly below the values at $1000 \mathrm{kPa}$. As can be seen in Figure 10, the increased spray cone angle in the spill-controlled regime shifted the velocity maxima to larger radial distances. The both spillcontrolled regimes produced finer sprays than the regimes without spill control at comparable inlet pressures.

SMD of droplets in the case of Nozzle 2 changed even more significantly with increasing gauge pressure (Figure 11) than in the case of Nozzle 1. The SMD variation with radial distance is less distinct; the radial SMD profiles are inversely bell-shaped at high pressures and change to almost flat profiles when gauge pressure decreases. The SMD span within the radial profile ranged from $36 \mu \mathrm{m}$ (from 82 to $118 \mu \mathrm{m}$ ) for regime 1 up to 76 $\mu \mathrm{m}$ (from 14 to $90 \mu \mathrm{m}$ ) for regime 4 which was less than for Nozzle 1. At low pressure, particles with the largest diameter were concentrated close to the spray axis (area of the greatest mass flux).

Comparison of SMD values in radial profiles of the both nozzles (Figure 9 vs. 11) shows that Nozzle 2 produced finer spray for the same pressure differential. Its SMD at individual radial positions (except close the nozzle centreline), was lower by $\sim 5-20 \mu \mathrm{m}$ at low pressures and $\sim 15-20 \mu \mathrm{m}$ at high pressures. These differences in SMD distribution might significantly affect the combustion process.

\subsection{Combustion-relevant spray parameters}

The mean drop size is the main parameter affecting pollutants formation such as $\mathrm{CO}$, unburned hydrocarbons (UHC), $\mathrm{NO}_{\mathrm{x}}$, and particulate matter (soot) [8]. Nozzle 1 generated finer and wider spray at low inlet pressure with the spill valve open in comparison to the narrow coarse spray generated by Nozzle 2. At high air/fuel rations that generally occur at engine idle $(\sim 100)$ CO and UHC emission reach their maxima. Smaller droplets evaporate faster and more volume is available for the chemical reaction resulting in lower CO and UHC emissions. Therefore, Nozzle 1 would potentially perform better in this regard at engine idle.

With increasing engine thrust (and pressure and temperature in the combustion chamber), $\mathrm{NO}_{\mathrm{x}}$ and soot are the dominant pollutants from single annular combustor engines [8]. Nozzle 2 that generated finer spray at high inlet pressures could potentially perform better in terms of high thrust emissions. In general, larger droplets burn in the diffusion flame mode at near stochastic fuel/air ratios. In these high temperature regions, $\mathrm{NO}_{\mathrm{x}}$ is formed by oxidation of the atmospheric nitrogen. Smaller droplets burn in the premix flame mode at higher local air/fuel ratios. They have, on one hand, time to evaporate completely ahead of the flame front, reducing the soot formation. On the other hand, the reduced spray penetration due to lower droplets momentum may actually increase 
the soot emissions because of the local increase in fuel concentration in the primary combustion zone. This aspect needs to be investigated on a combustion test rig. Overall, more stable operation, smaller mean drop size, and wider spray angle of Nozzle 2 could promote stable heat release rate and pollutants reduction during engine cruise and take-off.

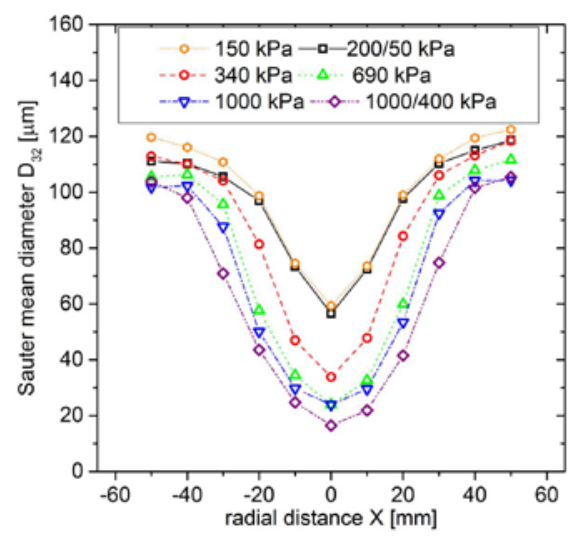

Figure 9 Nozzle 1, Sauter mean diameter at $z=50 \mathrm{~mm}$.

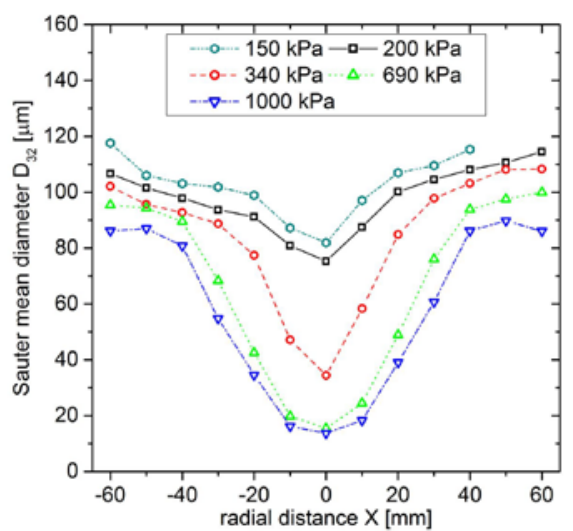

Figure 11 Nozzle 2, Sauter mean diameter at $z=50 \mathrm{~mm}$.

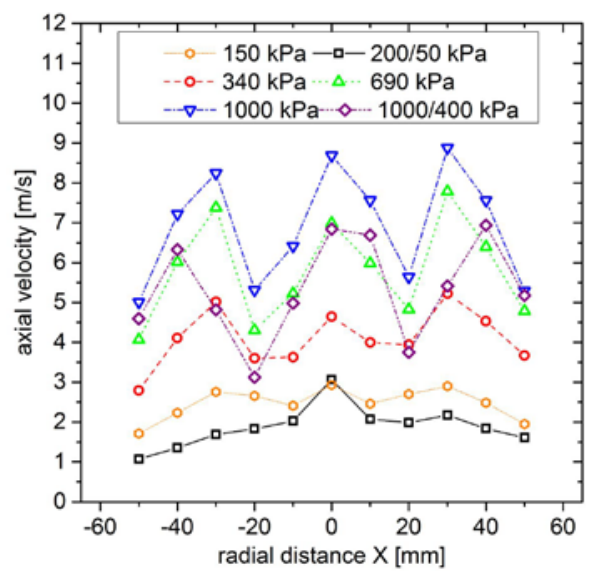

Figure 10 Nozzle 1, axial velocity profiles at $z=50 \mathrm{~mm}$.

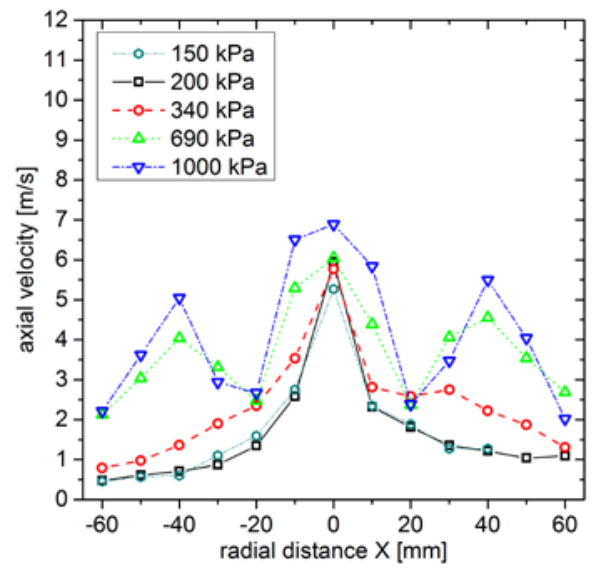

Figure 12 Nozzle 2, axial velocity profiles at $z=50 \mathrm{~mm}$.

\section{Summary and Conclusions}

Characteristics of sprays generated by two geometrically different pressure-swirl atomizers for a combustion chamber of a small-sized jet engine were investigated using the measurement techniques Particle Image Velocimetry and Phase-Doppler Anemometry. Jet A-1 aviation fuel was used as the working liquid on the cold test bench in a wide range of fuel inlet pressures. The former nozzle (Nozzle 1) was a spill-return type and the latter one was a newly designed simplex nozzle (Nozzle 2). It was observed that these nozzles generated sprays with different quality and morphology when compared for the same operating conditions:

- $\quad$ Nozzle 1 generated a hollow-cone spray with only moderate increase in spray cone angle with increasing inlet pressure. Following effects of spill fuel flow on atomization quality were observed: drop-size distribution in spill-controlled operating regimes was shifted towards lower SMD values; spray cone angle increased with an increase of the fraction of the fuel spilled from the swirl chamber; droplet velocity was lower due to the decrease of the liquid sheet thickness. 
- $\quad$ Spray characteristics of Nozzle 2, namely the spray cone angle, were found to be highly dependent on fuel injection pressure. For lower values below $300 \mathrm{kPa}$, the nozzle generated a full-cone spray with the liquid mass concentrated in the centre and with increasing pressure changed into a hollow-cone spray.

- $\quad$ Nozzle 2 produced finer spray for comparable regimes with SMD lower by about 5-20 $\mu m$ depending on the pressure differential.

- Droplet clustering occurred in the spray core of Nozzle 2 due to small droplets present there.

Further findings, acquired during the study, are related to pressure-swirl sprays more generally, without the accent on the nozzle comparison:

- Droplet velocity is highly spatially variable with its maximum near the exit orifice according the PIV results. The original liquid momentum is well conserved near the exit orifice. Decreasing droplet size during the breakup and increasing interfacial area cause rapidly intensified droplet interaction with air downstream and quick reduction of droplet momentum. The velocity decay along distance from the nozzle is very intense at high pressure and open spill line regimes. Nozzle 2 shows increased decay rate of droplet momentum due to finer spray and wider cone angles.

- A locally-high velocity magnitude, placed near the spray centreline, was found in the sprays from both atomizers at a range of operation pressures. We were not able to fully explain this behaviour, noticed also by several other authors.

- We observed two spray modes with a distinct spatial distribution of droplets within the spray: full-cone geometry at low pressures and hollow conical spray structure at sufficient inlet pressure (about $500 \mathrm{kPa}$ for both the nozzles). Drop size was relatively spatially uniform at the full-cone mode showing almost flat radial SMD profiles. Small droplets appeared in the spray core and large ones at the conical spray envelope in the hollow-cone mode which results in inversely bell-shaped radial SMD profiles.

- $\quad$ Stereoscopic PIV resolved the tangential component of the droplet velocity; it was highly spatially variable with maximum values of several $\mathrm{m} / \mathrm{s}$ and decaying close to zero with increasing downstream distance similarly for both the nozzles. Influence of this component on the velocity magnitude was found insignificant since the estimated tangential velocity was of one order of magnitude lower than corresponding axial velocity component.

Investigated differences in spray characteristics will most likely cause different behaviour of the nozzles in the combustion chamber. Distinct spray geometry, drop-size and velocity distribution will cause different interaction of the fuel with ambient air, evaporation rate, and subsequent heat release during the combustion process as well as soot formation in the proximity of the nozzle. The novel atomizer will also have other requirements on the power regulation of the engine. It is very probable that the original combustion chamber, which is optimized for the former spill-return nozzle, will require design optimization for the new one.

Further work will be focused on the optimization of the PIV configuration and application of advanced processing algorithms and decomposition methods to acquire new information about the spray behaviour.

\section{Conflict of Interests}

The authors declare that there is no conflict of interests regarding the publication of this paper.

\section{Acknowledgements}

Authors acknowledge financial support from project No. P101/11/1264 funded by the Czech Science Foundation and NETME Centre, regional R\&D centre built with the financial support from the Operational Programme "Research and Development for Innovations" within the project "NETME Centre (New Technologies for Mechanical Engineering)”, Reg. No. CZ.1.05/2.1.00/01.0002 and, in the follow-up sustainability stage, supported through NETME CENTRE PLUS (LO1202) by financial means from the Ministry of Education, Youth and Sports under the "National Sustainability Programme I".

\section{References}

[1] Adrian, R. J., and Westerweel, J., Particle Image Velocimetry, Cambridge University Press, 584 p., ISBN 978-0521440080 (2011).

[2] Belhadef, A., Vallet, A., Amielh, M., and Anselmet, F., Pressure-swirl atomization: Modeling and experimental approaches, Int. Journal of Multiphase Flow 39, p. 13-20 (2012).

[3] Carey, F. H., The Development of the Spill Flow Burner and Its Control System for Gas Turbine Engines. Journal of the Royal Aeronautical Society 58 (1954).

[4] Chu, C., Chou, S., Lin, H., and Liann Y., An Experimental Investigation of Swirl Atomizer Sprays, Heat and Mass Transfer 45: 11-22 (2008). DOI:10.1007/s00231-008-0389-1

[5] Durdina, L., Jedelsky, J., and Jicha, M., PIV Investigation of a Pressure-Swirl Atomizer Spray, Engineering Mechanics, Vol. 20, No. 6, p. 1-11 (2013). 
[6] Herpfer, D. C., and Jeng, S.-M., Planar measurements of droplet velocities and sizes within a simplex atomizer, AIAA journal, 35, p. 127-132 (1997).

[7] Kohse-Hoeinghaus, K., and Jeffries, J. B. (Ed.), Applied Combustion Diagnostics, Taylor\&Francis (2002).

[8] Lefebvre, A. H., and Ballal, D. R., Gas Turbine Combustion, $3^{\text {rd }}$ edition, Taylor \& Francis, 560 p. ISBN 978-1-4200-8605-8, (2010).

[9] Lefebvre, A. H., Atomization and Sprays, New York: Hemisphere Publishing Corp. 421 p. (1989).

[10]Li, T., Nishida, K., and Hiroyasu, H., Droplet size distribution and evaporation characteristics of fuel spray by a swirl type atomizer, Fuel, 90-7, p. 2367-2376 (2011).

[11] Madsen, J. Computational and experimental study of sprays from the breakup of water sheets. PhD thesis, Aalborg University (2006).

[12] Marchione, T., Allouis, C., Amoresano, A., and Beretta, F., Experimental investigation of a pressure swirl atomizer spray. Journal of Propulsion and Power, 23, p. 1096-1101 (2007).

[13] Muliadi, A.R, Sojka, P. E., Sivathanu, Y. R., and Lim, J., A Comparison of Phase Doppler Analyzer (DualPDA) and Optical Patternator Data for Twin-Fluid and Pressure-Swirl Atomizer Sprays, Journal of Fluids Engineering, Transactions of the ASME 132, no. 6: 061402-061412 (2010).

[14] Nasr, G. G., Yule, A. J., Stewart, J. A., Whitehead, A., and Hughes, T., A new fine spray, low flowrate, spill-return swirl atomizer. Proceedings of the Institution of Mechanical Engineers, Part C: Journal of Mechanical Engineering Science, 2011. 225(4): p. 897-908.

[15] Quentin, F., ACARE: the European Technology Platform for Aeronautics, December 2007. Available online: ftp://ftp.cordis.europa.eu/pub/etp/docs/acare_en.pdf

[16]Rizk, N. K., and Lefebvre, A. H., Prediction of Velocity Coefficient and Spray Cone Angle for Simplex Atomizers. In ICLASS-85 Proceedings (1985).

[17] Rizk, N. K., and Lefebvre, A. H., Internal Flow Characteristics of Simplex Swirl Atomizers, Journal of Propulsion and Power 1, p. 193-199 (1985).

[18] Rizk, N. K., and Lefebvre, A. H., Drop-Size Distribution Characteristics of Spill-Return Atomizers, Journal of Propulsion and Power 1-1, p. 16-22 (1985).

[19] Rizk, N. K., and Lefebvre, A. H., Spray Characteristics of Spill-Return Atomizers, Journal of Propulsion and Power 1-3, p. 200-204 (1985).

[20] Santolaya, J., Aisa, L., Calvo, E., García, I. and Cerecedo, L., Experimental study of near-field flow structure in hollow cone pressure swirl sprays, Journal of propulsion and power, 23, p. 382-389 (2007).

[21] Squire, H. B., Investigation of the Instability of a Moving Liquid Film, British Journal of Applied Physics 4, p. 1697-1969 (1953).

[22] Taylor, G. I., The Mechanics of Swirl Atomizers, Seventh International Congress of Applied Mechanics 2 (1948).

[23] Wang, X. F., and Lefebvre, A. H., Influence of Ambient Air Pressure on Pressure-Swirl Atomization, Atomisation and Spray Technology 3 (1987).

[24] Wang, X. F., and Lefebvre, A. H., Mean Drop Sizes From Pressure-Swirl Nozzles, Journal of Propulsion and Power 3-1, p. 11-18 (1987).

[25] Xie, J. L., Gan, Z. W., Duan, F., Wong, T. N., Yu, S. C. M., and Zhao, R., Characterization of spray atomization and heat transfer of pressure swirl nozzles, International Journal of Thermal Sciences, 44, 9 (2013).

[26] Yan, Y., Zhang, L., Pan, W., and Pu, G., Experimental Investigation of Atomizing Performance of Low Pressure Swirl Nozzle, Advances in Mechanical Engineering, Vol. 2014, 10 p., http://dx.doi.org/10.1155/2014/782064 (2014).

[27] Yang, J., Chen, A., Yang, S., and Huang, K, In Flow analysis of spray patterns of pressure-swirl micro atomizers, Pacific Symposium on Flow Visualization and Image Processing (2003).

[28] Yao, Sh., Zhang, J., and Fang, T., Effect of viscosities on structure and instability of sprays from a swirl atomizer, Experimental Thermal and Fluid Science 39, p. 158-166 (2012). 